\title{
Comparison of surgical outcomes and complications between the Harmonic FOCUS and conventional surgery for open thyroidectomy
}

\author{
HIDEKI MAEDA $^{1}$, GORO KUTOMI ${ }^{1}$, FUKINO SATOMI ${ }^{1}$, \\ HIROAKI SHIMA $^{1}$, MITSURU MORI ${ }^{2}$ and ICHIRO TAKEMASA ${ }^{1}$ \\ ${ }^{1}$ Department of Surgery, Surgical Oncology and Science, Sapporo Medical University, Sapporo, Hokkaido 060-8543; \\ ${ }^{2}$ Department of Public Health, Sapporo Medical University, Sapporo, Hokkaido 060-8556, Japan
}

Received March 29, 2017; Accepted August 17, 2017

DOI: $10.3892 / \mathrm{mco} .2018 .1569$

\begin{abstract}
The aim of the present study was to evaluate the potential advantages of the ultrasonic scalpel compared with the conventional technique in thyroid surgery. Patients with resectable thyroid cancer and Basedow's disease were assigned to ultrasonic scalpel or conventional technique (knot-tying and electrocoagulation). The present study used the Harmonic FOCUS $^{\circledR}$ (HF) as an ultrasonic scalpel. Between February 2013 and May 2016, 45 patients were enrolled into the study. Duration of the surgery was significantly decreased in the HF group compared with the conventional surgery (CS) group (median 142 vs. $151 \mathrm{~min} ; \mathrm{P}=0.0406$ ). Intraoperative blood loss and total volume of drainage fluid were significantly decreased in the HF group compared with the CS group (median 40 vs. $125 \mathrm{ml} ; \mathrm{P}=0.0054$, and median 120 vs. $175.5 \mathrm{ml}$; $\mathrm{P}=0.0490$ ). Duration of drain placement and length of hospitalization stay were similar in the two groups. Furthermore, the overall incidence of postoperative complications did not differ between the two groups. Overall, the present study suggests that open thyroidectomy using the HF is safe and effective and not associated with any increase in complications.
\end{abstract}

\section{Introduction}

In endocrine surgery, thyroid surgery is the most commonly performed. Complications of thyroid surgery include bleeding, damage to the recurrent laryngeal nerve (RLN) and superior laryngeal nerve, and hypoparathyroidism. Intraoperative bleeding is common in thyroid surgery because of the narrow visual field and presence of several small blood vessels (1). In

Correspondence to: Dr Goro Kutomi, Department of Surgery, Surgical Oncology and Science, Sapporo Medical University, S1 W17 Chuo-ku, Sapporo, Hokkaido 060-8543, Japan

E-mail:kutomi@sapmed.ac.jp

Key words: comparison, conventional surgery, Harmonic FOCUS, open thyroidectomy, hemostasis such a setting, bleeding is liable to trigger various complications; postoperative bleeding in particular can block the airways and occasionally cause complications. Therefore, it is imperative to perform blood vessel dissection and hemostasis in a dry surgical field.

The Harmonic FOCUS ${ }^{\circledR}$ (HF; Ethicon Endo-Surgery, Inc.) comprises a range of ultrasonic surgical devices that enable simultaneous dissection and coagulation of tissue (2). Ultrasonic waves are created by electromagnetic energy from a generator, which undergoes piezoelectric transduction within the hand piece. The blade of the HF vibrates at $55 \mathrm{kHz}$, producing mechanical energy that breaks hydrogen bonds. The HF is hand-activated, with cutting and sealing of vessels achieved by placing the curved blade in contact with the tissue and applying pressure (3).

Ultrasonic coagulation and incision instruments were purchased within the purview of medical insurance coverage in 1998 following the approval of their use in laparoscopic and thoracoscopic surgery. Subsequently, these instruments have been used in an ever-widening range of open and laparoscopic surgeries including those for malignant tumors. It has been claimed that the use of the HF decreases the duration of surgery, intraoperative blood loss, volume of drainage fluid and postoperative complications in abdominal laparoscopic surgery (4), thoracic surgery (5) and parotid surgery (6).

Recently, some reports have demonstrated the efficacy of their use in thyroidectomy in terms of reduction of surgical time and other postoperative outcomes (1,7-9). Therefore, numerous surgeons who perform thyroid surgery use the HF.

This was a retrospective clinical study based on prospectively collected data to assess the use of the HF for open thyroidectomy. The aim of the present study was to compare surgical outcomes between the HF and conventional techniques in open thyroidectomy and evaluate any significant difference in results.

\section{Patients and methods}

A total of 45 patients with thyroid disease treated at the Department of Surgery, Surgical Oncology and Science of the Sapporo Medical University Hospital (Sapporo, Japan) between 
February 2013 and May 2016 were retrospectively analyzed in the present study. We examined consecutive patients aged $\geq 18$ years who underwent total thyroidectomy or partial thyroidectomy for thyroid malignancy or Basedow's disease with indications for surgery, irrespective of the presence or absence of lymph node dissection. Patients were divided into two groups: Those who underwent surgery with HF group $(n=21)$ and those who underwent conventional surgery group $(n=24)$ performed with electric scalpel and ligation.

All the surgeries were performed by a total of three surgeons, two of whom had 16 years of experience and one had 11 years of experience. The HF was gradually introduced from May 2015 and was used in all of the cases in 2015-2016.

Surgical procedures were performed under general anesthesia with endotracheal intubation. In surgeries performed with $\mathrm{HF}$, the approach to the thyroid involved transection of the sternohyoid and the sternothyroid muscles, and most of the dissections after skin flap creation were performed using HF (Fig. 1). The superior and inferior thyroid arteries and veins with diameter of $\geq 5 \mathrm{~mm}$ were ligated and dissected; for all other blood vessels, the MIN mode of HF was used. HF was used for dissection at the anterior surface of the trachea including that of the Berry's ligament. For thyroid lobectomy, coagulation and resection was performed in the MIN mode.

The present study was performed according to the Ethical Guidelines for Clinical Research of the Japanese Ministry of Health, Labor and Welfare. An independent ethics committee for each participating site approved the protocol and any modifications. Written informed consent was obtained from all patients or the patient's family.

Outcomes. The primary outcomes included duration of surgery (in min) from the start of the incision until closure, intraoperative estimated blood loss $(\mathrm{ml})$, volume of drainage fluid in the first $24 \mathrm{~h}$ following surgery, volume of drainage fluid until drain removal (ml), duration of drain placement (days), and length of hospitalization stay (days). The drain was removed once the volume of drainage fluid was $<10 \mathrm{ml}$ for 1 day.

Secondary outcomes, which took safety into consideration, included postoperative RLN paralysis, postoperative hypocalcemia, postoperative bleeding that required surgical intervention, and postoperative chylous fistula. Permanent RLN was defined as paralysis that was present 1 year after surgery. RLN paresis needed to be determined via laryngoscopy. Postoperative hypocalcaemia was only evaluated for patients receiving a total thyroidectomy (with or without neck dissection). Permanent hypocalcaemia was defined as a need for vitamin D or calcium supplementation 1 year after surgery.

Statistical analysis. Results are presented as mean values \pm standard deviation. Comparisons between the two groups were assessed with the two-sample t test, Chi-square test. The non-parametric Mann-Whitney U test was used to compare the operative and postoperative parameters between the HF and CS groups. The quantitative operative and postoperative parameters are expressed as medians with their interquartile range (IQR). Differences were considered significant when $\mathrm{P}<0.05$. Statistical analysis was performed using SAS, version 9.4 (SAS Institute, Cary, NC, USA).

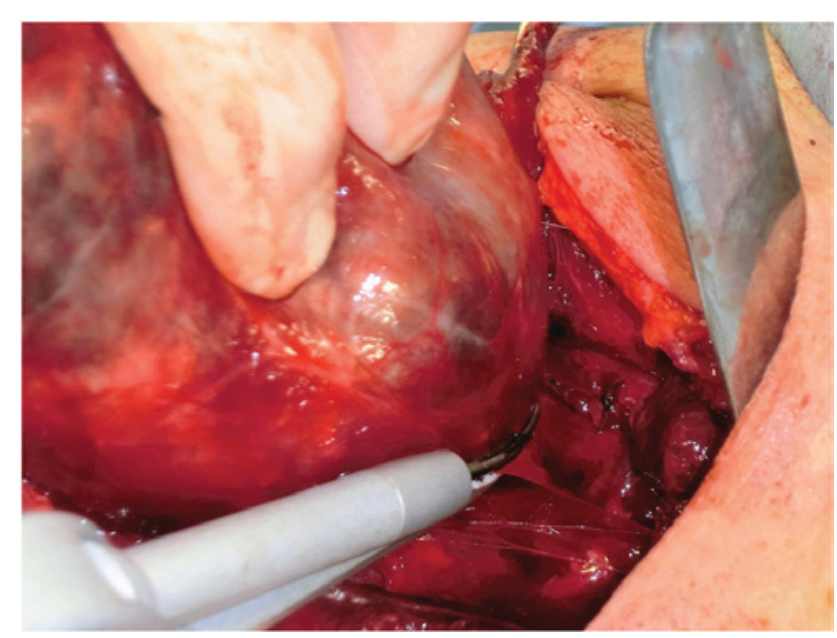

Figure 1. Dissection and division of the superior pedicle using the Harmonic FOCUS.

\section{Results}

Forty-five patients who underwent total or partial thyroidectomy were enrolled in the present study, irrespective of whether the disease was benign or malignant. The demographic information of the study are summarized in Table I. No significant difference was observed between the two groups with respect to patient attributes [sex, age, body mass index, and nature of disease (benign or malignant)]. With regards to the surgical procedure (total or partial thyroidectomy), total thyroidectomy was performed with HF in 6 patients $(29 \%)$ and with CS in 10 patients (42\%), whereas the latter group had more patients; the difference was not statistically significant.

Duration of surgery was significantly shorter in the HF group compared with the CS group [median (IQR): 142 min (121-160) vs. $151 \mathrm{~min}$ (136.8-299.3); P=0.0406] (Fig. 2A). Intraoperative blood loss was significantly less in the HF group [median (IQR): $40 \mathrm{ml}(0-80)$ vs. $125 \mathrm{ml}$ (50-176.3); $\mathrm{P}=0.0054$ ] (Fig. 2B). While there was no significant difference in the volume of drainage fluid in the first $24 \mathrm{~h}$ post-surgery [median (IQR): $55 \mathrm{ml}$ (30-80) vs. $50 \mathrm{ml}$ (30-90)] (Fig. 2C), the overall volume of drainage fluid until drain removal was significantly lower in the HF group [median (IQR): $120 \mathrm{ml}$ (90-175) vs. $177.5 \mathrm{ml}$ (110-288.8); $\mathrm{P}=0.0490$ ] (Fig. 2D). There was no significant difference between the two groups with respect to the duration of drain placement [median (IQR): 4 days (3-4) vs. 5 days (4-5.25)] (Fig. 2E) and length of hospitalization stay [median (IQR): 7 days (6-9) vs. 6 days (5.75-7)] (Fig. 2F).

Postoperative complications occurred in two patients in the HF group and three in the CS group (Table II). Temporary RLN paralysis and temporary hypocalcemia occurred in one patient in both groups. In the CS group that underwent total thyroidectomy + neck dissection, one patient developed postoperative chylous fistula. In this patient, postoperative chylous fistula was diagnosed based on increased volume and milky appearance of the drainage fluid after recommencement of meals; however, symptoms were alleviated with one week of fasting, continued negative pressure drainage, and total parenteral nutrition. There was no significant difference in the incidence of complications between the two groups $(\mathrm{P}=0.7513)$. 
Table I. Demographic parameters in the HF and CS groups.

\begin{tabular}{lccc}
\hline Parameter & HF $(\mathrm{n}=21)$ & $\mathrm{CS}(\mathrm{n}=24)$ & P-value \\
\hline Sex (\%) & & & $0.8812^{\mathrm{a}}$ \\
Male & $4(19)$ & $5(21)$ & \\
Female & $17(81)$ & $19(79)$ & \\
Age & $51.5 \pm 11.84$ & $57.8 \pm 13.73$ & $0.1039^{\mathrm{b}}$ \\
BMI $\left(\mathrm{kg} / \mathrm{m}^{2}\right)$ & $23.6 \pm 3.42$ & $23.7 \pm 3.93$ & $0.9780^{\mathrm{b}}$ \\
Nature of disease (\%) & & & \\
$\quad$ Benign & $7(33)$ & $8(33)$ & \\
$\quad$ Malignancy & $14(66)$ & $16(66)$ & \\
Extent of surgery (\%) & & & $0.3599^{\mathrm{a}}$ \\
$\quad$ Total thyroidectomy & $6(29)$ & $10(42)$ & \\
$\quad$ Partial thyroidectomy & $15(71)$ & $14(58)$ & \\
\end{tabular}

${ }^{\mathrm{a}} \chi^{2}$ test; 'btudent's t-test. HF, Harmonic FOCUS; CS, conventional surgery.
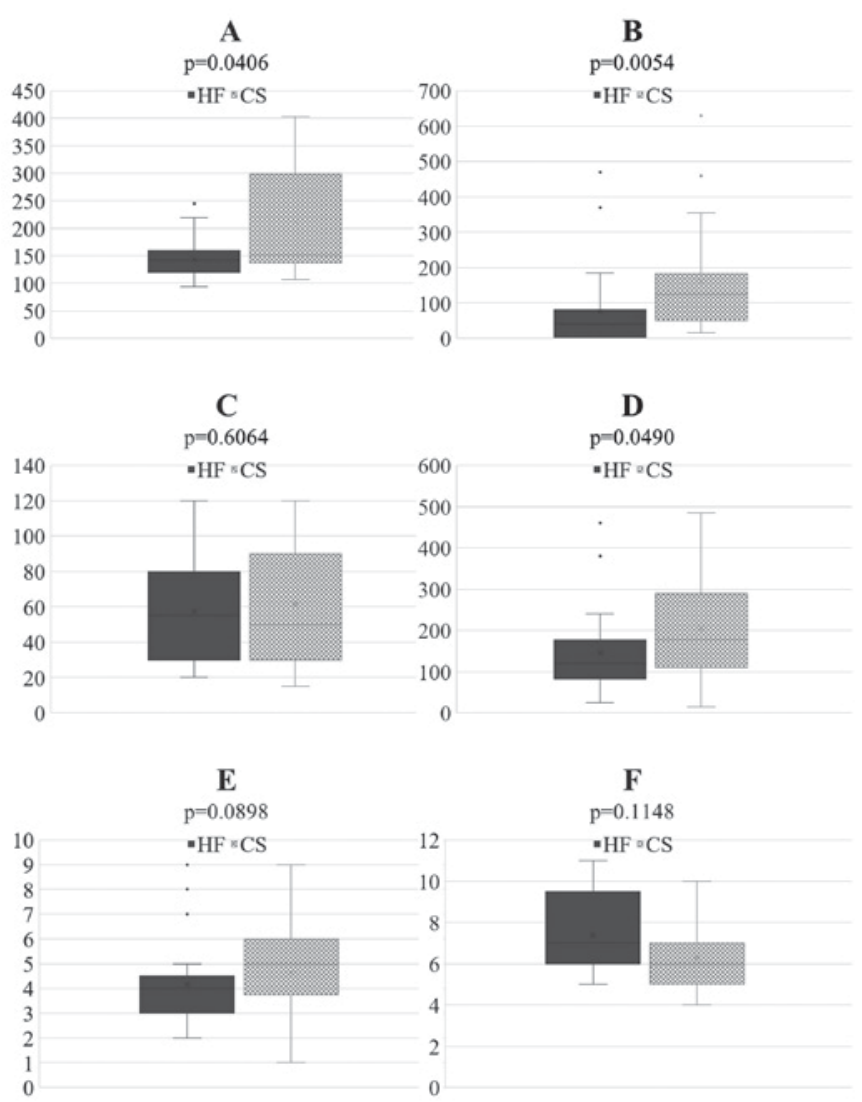

Figure 2. Operative and postoperative data in HF (Harmonic FOCUS) and CS (Conventional Surgery) groups. Box plot corresponding to (A) duration of surgery (min), (B) intraoperative blood loss (ml), (C) POD1 volume of drainage fluid (ml), (D) total volume of drainage fluid (ml), (E) duration of drain placement (days), and (F) length of hospitalization stay (days).

\section{Discussion}

In the present study, we compared the outcomes of open thyroidectomy performed using HF with those performed using the conventional clamp-and-tie technique. In our
Table II. Postoperative surgical complications between the HF and CS groups.

\begin{tabular}{lccc}
\hline Parameter & HF $(\mathrm{n}=21)$ & $\mathrm{CS}(\mathrm{n}=24)$ & P-value \\
\hline $\begin{array}{l}\text { Complications } \\
\text { Temporary paralysis } \\
\text { of RLN }\end{array}$ & $2(9.5 \%)$ & $3(12.5 \%)$ & $0.7513^{\mathrm{a}}$ \\
$\begin{array}{l}\text { Permanent paralysis } \\
\text { of RLN }\end{array}$ & 0 & 1 & \\
$\begin{array}{l}\text { Temporary } \\
\text { hypocalcaemia }\end{array}$ & 1 & 0 & \\
$\begin{array}{l}\text { Permanent } \\
\text { hypocalcaemia }\end{array}$ & 0 & 1 & \\
$\begin{array}{l}\text { Hemorrhage } \\
\text { requiring surgery }\end{array}$ & 0 & 0 & \\
$\begin{array}{l}\text { Chyle fistula } \\
\text { Surgical } \\
\text { site infection }\end{array}$ & 0 & 0 & \\
\hline
\end{tabular}

${ }^{\mathrm{a}} \chi^{2}$ test. RLN, recurrent laryngeal nerve; HF, harmonic FOCUS; $\mathrm{CS}$, conventional surgery.

experience, the use of HF is useful in shortening the duration of thyroid surgery. This is likely attributable to the fact that tissue can be detached, coagulated, and dissected with HF in a continuous operation without the need to change instruments. The characteristics of HF, i.e., the double-action jaws, shape similar to that of the Kelly forceps used for pediatric procedures, and curved, long, and narrow blades render it particularly suited for thyroid surgery. On the basis of our experience, surgeons who are generally capable of conventional thyroid surgery do not require a particular learning period to master the use of HF.

Some negative reports indicate that routine drain placement following thyroidectomy is not effective in reducing the incidence of postoperative complications and that it may prolong hospital stay and cause infection of the surgical site. However, our surgical team placed drains in all patients who underwent thyroidectomy. Although drain use is not routine and it is not necessary in conventional thyroidectomy techniques as discussed in the literature (10), it was used by our surgical team in all the patients in the two groups.

During thyroid surgery, particular care should be paid so as not to damage the RLN. In clinical studies, the incidence of temporary RLN paralysis associated with the use of HF for total thyroidectomy was $0.7-5.6 \%$ (11). Wu et al examined the effect of use of HF on RLN in a porcine model with continuous electrophysiological monitoring; they noted that the active blade should be at a distance of at least $1 \mathrm{~mm}$ from the RLN to ensure safety (12). Furthermore, in a similar experimental model using porcine small intestines, intermittent use of the harmonic operation significantly reduced thermal damage to the surrounding tissues. A continuous activation time of no more than $5 \mathrm{sec}$ is recommended (13). With regards to treatment near the RLN, nerve orientation is confirmed as per CS without using HF by lifting the connective tissue of the 
anterior surface of the nerve with forceps at a safe distance from the nerve followed by careful blunt dissection.

As is the case in any type of surgery, shorter surgical duration reduces the risk of surgical-site infection and accelerates patient recovery (14). The use of HF helps decrease the rate of adverse events such as RLN paralysis and intraoperative blood loss. Furthermore, shorter surgical duration was desirable from a cost perspective $(15,16)$.

The present study has several limitations. The first limitation is the small sample size. Reported outcomes are potentially influenced by surgeon experience and other procedural details which may have varied across the studies. Furthermore, the underlying thyroid diseases in the study included both benign and malignant diseases; differences with respect to tumor size and pathological background may have influenced the level of surgical difficulty.

Future studies should assess the areas of surgery where HF would be effective and where it should be avoided. Further studies should assess the level of skill required and cost effectiveness of this surgery.

In conclusion, from this present study, the use of HF reduced the duration of surgery, intraoperative blood loss, and total volume of postoperative drainage fluid and did not increase complications. Therefore, HF is a safe and reliable tool for use in thyroid surgery and more effective than electric scalpel and ligatures used in CS.

\section{Acknowledgements}

The present study was supported by a grant from the Yuasa Memorial Foundation. The authors are grateful to all the study participants.

\section{References}

1. Garas G, Okabayashi K, Ashrafian H, Shetty K, Palazzo F, Tolley N, Darzi A, Athanasiou T and Zacharakis E: Which hemostatic device in thyroid surgery? A network meta-analysis of surgical technologies. Thyroid 23: 1138-1150, 2013.

2. Contin P, Gooßen K, Grummich K, Jensen K, SchmitzWinnenthal H, Büchler MW and Diener MK: ENERgized vessel sealing systems versus CONventional hemostasis techniques in thyroid surgery-the ENERCON systematic review and network meta-analysis. Langenbecks Arch Surg 398: 1039-1056, 2013.

3. Cannizzaro MA, Borzì L, Lo Bianco S, Okatyeva V, Cavallaro A and Buffone A: Comparison between Focus Harmonic scalpel and other hemostatic techniques in open thyroidectomy: A systematic review and meta-analysis. Head Neck 38: 1571-1578, 2016.
4. Caglià P, Costa S, Tracia A, Veroux M, Luca S, Zappulla E, Russo V, Lucifora B, Borzì L, Patanè G, et al: Can laparoscopic cholecystectomy be safety performed in the elderly? Ann Ital Chir 83: 21-24, 2012.

5. Takagi K, Hata Y, Sasamoto S, Tamaki K, Fukumori K, Otsuka H, Hasegawa C and Shibuya K: Late onset postoperative pulmonary fistula following a pulmonary segmentectomy using electrocautery or a harmonic scalpel. Ann Thorac Cardiovasc Surg 16: 21-25, 2010.

6. Prgomet D, Janjanin S, Bilić M, Prstacić R, Kovac L, Rudes M and Katić V: A prospective observational study of 363 cases operated with three different harmonic scalpels. Eur Arch Otorhinolaryngol 266: 1965-1970, 2009.

7. Parmeggiani D, De Falco M, Avenia N, Sanguinetti A Fiore A, Docimo G, Ambrosino P, Madonna I, Peltrini R and Parmeggiani U: Nerve sparing sutureless total thyroidectomy. Preliminary study. Ann Ital Chir 83: 91-96, 2012.

8. Minni A, Rosati D, Cavaliere C, De Carlo A, Illuminati G, Scarano Catanzaro V and Bodoni M: Study on the use of focus harmonic scalpel in thyroidectomies: Is it useful also in preserving voice function? Eur Rev Med Pharmacol Sci 20: 3544-3551, 2016.

9. Al-Dhahiry JK and Hameed HM: Total thyroidectomy: Conventional suture ligation technique versus sutureless techniques using harmonic scalpel or maxium. Ann Med Surg (Lond) 5: 29-34, 2015.

10. Ozlem N, Ozdogan M, Gurer A, Gomceli I and Aydin R: Should the thyroid bed be drained after thyroidectomy? Langenbecks Arch Surg 391: 228-230, 2006.

11. Lang BH, Ng SH, Lau LL, Cowling BJ and Wong KP: A systematic review and meta-analysis comparing the efficacy and surgical outcomes of total thyroidectomy between harmonic scalpel versus ligasure. Ann Surg Oncol 20: 1918-1926, 2013.

12. Wu CW, Chai YJ, Dionigi G, Chiang FY, Liu X, Sun H, Randolph GW, Tufano RP and Kim HY: Recurrent laryngeal nerve safety parameters of the Harmonic Focus during thyroid surgery: Porcine model using continuous monitoring. Laryngoscope 125: 2838-2845, 2015.

13. Pogorelić Z, Perko Z, Druzijanić N, Tomić S and Mrklić I: How to prevent lateral thermal damage to tissue using the harmonic scalpel: Experimental study on pig small intestine and abdominal wall. Eur Surg Res 43: 235-240, 2009.

14. Elfenbein DM, Schneider DF, Chen H and Sippel RS: Surgical site infection after thyroidectomy: A rare but significant complication. J Surg Res 190: 170-176, 2014.

15. Pons Y, Gauthier J, Ukkola-Pons E, Clément P, Roguet E, Poncet JL and Conessa C: Comparison of LigaSure vessel sealing system, harmonic scalpel and conventional hemostasis in total thyroidectomy. Otolaryngol Head Neck Surg 141: 496-501, 2009.

16. Konturek A, Barczyński M, Stopa M and Nowak W: Total thyroidectomy for non-toxic multinodular goiter with versus without the use of harmonic FOCUS dissecting shears-a prospective randomized study. Wideochir Inne Tech Maloinwazyjne 7: 268-274, 2012. 